non-governmental, non-profit organization whose members act as the IOC's representatives in their respective countries, not as delegates of their countries within the IOC. The Committee's main responsibility is to supervise the organization of the summer and winter Olympic Games. It owns all rights to the Olympic symbols, flag, motto, anthem and Olympic Games.

Aims. 'To contribute to building a peaceful and better world by educating youth through sport, practised without discrimination of any kind and in the Olympic Spirit, which requires mutual understanding with a spirit of friendship, solidarity and fair play.'

Finances. The IOC receives no public funding. Its only source of funding is from private sectors, with the substantial part of these revenues coming from television broadcasters and sponsors.

Address: Château de Vidy, Case Postale 356, CH-1007 Lausanne, Switzerland.

Website: http://www.olympic.org

President: Jacques Rogge (Belgium).

\section{International Organisation of La Francophonie}

The International Organisation of La Francophonie represents 70 countries and provinces/regions (including 14 with observer status) using French as an official language. It estimates that there are $220 \mathrm{~m}$. French speakers worldwide. Objectives include the promotion of peace, democracy, and economic and social development, through political and technical co-operation. The Secretary-General is based in Paris.

Members. Albania, Andorra, Belgium, Benin, Bulgaria, Burkina Faso, Burundi, Cambodia, Cameroon, Canada, Canada-New Brunswick, Canada-Quebec, Cape Verde, Central African Republic, Chad, Comoros, Democratic Republic of the Congo, Republic of the Congo, Côte d'Ivoire, Djibouti, Dominica, Egypt, Equatorial Guinea, France, French Community of Belgium, Gabon, Greece, Guinea, Guinea-Bissau, Haiti, Laos, Lebanon, Luxembourg, Macedonia, Madagascar, Mali, Mauritania, Mauritius, Moldova, Monaco, Morocco, Niger, Romania, Rwanda, St Lucia, São Tomé e Príncipe, Senegal, Seychelles, Switzerland, Togo, Tunisia, Vanuatu, Vietnam. Associate Members. Armenia, Cyprus, Ghana. Observers. Austria, Bosnia and Herzegovina, Croatia, Czech Republic, Dominican Republic, Estonia, Georgia, Hungary, Latvia, Lithuania, Montenegro, Mozambique, Poland, Serbia, Slovakia, Slovenia, Thailand, Ukraine, United Arab Emirates.

Headquarters: 19-21 avenue Bosquet, 75326 Paris, France. Website (limited English): http://www.francophonie.org Secretary-General: Abdou Diouf (Senegal).

\section{International Organization for Migration (IOM)}

Established in 1951, the International Organization for Migration (IOM) is dedicated to promoting humane and orderly migration. It does so by providing services and advice to governments and migrants.

Members (132 as of Feb. 2011). Afghanistan, Albania, Algeria, Angola, Argentina, Armenia, Australia, Austria, Azerbaijan, Bahamas, Bangladesh, Belarus, Belgium, Belize, Benin, Bolivia, Bosnia and Herzegovina, Botswana, Brazil, Bulgaria, Burkina
Faso, Burundi, Cambodia, Cameroon, Canada, Cape Verde, Central African Republic, Chile, Colombia, Democratic Republic of the Congo, Republic of the Congo, Costa Rica, Côte d'Ivoire, Croatia, Cyprus, Czech Republic, Denmark, Dominican Republic, Ecuador, Egypt, El Salvador, Estonia, Finland, France, Gabon, Gambia, Georgia, Germany, Ghana, Greece, Guatemala, Guinea, Guinea-Bissau, Haiti, Honduras, Hungary, India, Iran, Ireland, Israel, Italy, Jamaica, Japan, Jordan, Kazakhstan, Kenya, South Korea, Kyrgyzstan, Latvia, Lesotho, Liberia, Libya, Lithuania, Luxembourg, Madagascar, Mali, Malta, Mauritania, Mauritius, Mexico, Moldova, Mongolia, Montenegro, Morocco, Namibia, Nepal, Netherlands, New Zealand, Nicaragua, Niger, Nigeria, Norway, Pakistan, Panama, Paraguay, Peru, Philippines, Poland, Portugal, Romania, Rwanda, Senegal, Serbia, Sierra Leone, Slovakia, Slovenia, Somalia, South Africa, Spain, Sri Lanka, Sudan, Swaziland, Sweden, Switzerland, Tajikistan, United Republic of Tanzania, Thailand, Timor-Leste, Togo, Trinidad and Tobago, Tunisia, Turkey, Uganda, Ukraine, UK, USA, Uruguay, Venezuela, Vietnam, Yemen, Zambia and Zimbabwe. 17 countries and a large number of government agencies and NGOs have observer status.

Activities. IOM assists refugee populations during and after emergencies and facilitates their resettlement. IOM also helps find solutions for internally displaced persons (IDPs), former combatants, victims of ethnic engineering, and populations in transition or recovery environments. IOM activities that cut across these areas include the promotion of international migration law, the protection of migrants' rights, policy debate and guidance, migration health and the gender dimension of migration. Since 1952 IOM has directly assisted some 13m. migrants. In 2005 IOM launched its largest ever emergency response following the Indian Ocean tsunami in Dec. 2004. IOM's programme budget for 2008 exceeded US $\$ 1 \mathrm{bn}$., funding over 2,030 active programmes and more than 6,690 staff members serving in over 440 field offices in more than 100 countries.

Official languages: English, French, Spanish.

Headquarters: Route des Morillons 17, POB 71, 1211 Geneva 19, Switzerland.

Website: http://www.iom.int

Director-General: William Lacy Swing (USA).

\section{International Organization for Standardization (ISO)}

Established in 1947, the International Organization for Standardization is a non-governmental federation of national standards bodies from 157 countries worldwide, one from each country. ISO's work results in international agreements which are published as International Standards. The first ISO standard was published in 1951 with the title 'Standard reference temperature for industrial length measurement'.

Some 15,400 ISO International Standards are available on subjects in such diverse fields as information technology, textiles, packaging, distribution of goods, energy production and utilization, building, banking and financial services. ISO standardization activities include the widely recognized ISO 9000 family of quality management system and standards and the ISO 14000 series of environmental management system standards. Standardization programmes are now being developed in completely new fields, such as food safety, security, social responsibility and the service sector.

Mission. To promote the development of standardization and related activities in the world with a view to facilitating the 